\title{
AVALIAÇÃO DAS CONDIÇÕES DE CRESCIMENTO, FERMENTAÇÃO E COMPONENTES DO MEIO PARA PRODUÇÃO DE ACIDO D(-) LÁTICO MEDIANTE FERMENTAÇÃO POR Lactobacillus coryniformis sp. torquens
}

\author{
L.Y ACEVEDO JARAMILLO ${ }^{1}$, D. SILVEIRA SANTOS ${ }^{1}$, L. MELO SANTA ANNA ${ }^{2}$, \\ E. R. BORGES ${ }^{1}$ e N. PEREIRA Jr ${ }^{1}$. \\ ${ }^{1}$ Universidade Federal de Rio de Janeiro (UFRJ), Escola de Química, Laboratório de \\ Desenvolvimento de Bioprocesos LADEBIO \\ ${ }^{2}$ Centro de Pesquisa (CENPES), Petrobras \\ E-mail para contato: lizeth_jaramillo@hotmail.com
}

\begin{abstract}
RESUMO. O acido lático é considerado uma "commoditie" de ampla aplicação industrial, com $90 \%$ da produção mundial resultado de processo fermentativo. A forma isomérica $\mathrm{D}(-)$ lático e suas aplicações têm sido pouco exploradas, embora apresente um grande potencial na produção de biopolímeros. Inicialmente, foram alcançados $5,11 \mathrm{~g} / \mathrm{L}$ de biomassa celular e $17 \mathrm{~g} / \mathrm{L}$ de ácido lático a partir da fermentação do meio comercial MRS pela linhagem Lactobacillus corynifomis torquens. No seguinte, buscando a redução da quantidade de componentes do meio sintético, foi desenvolvido um planejamento de Plackett Burman, o qual promoveu a produção de biomassa entre os valores de $0,83 \mathrm{~g} / \mathrm{L}$ e 3,56 g/L. Os componentes que apresentaram maior influência nos ensaios, sendo selecionados para posteriores otimizações, foram os seguintes: extrato de carne, glicose, acetato de sódio, sulfato de magnésio e extrato de levedura. Adicionalmente, foi desenvolvido um planejamento fatorial completo, avaliando a agitação (rpm), o percentual de inoculo (v/v) e a concentração inicial de glicose (g/L). Além da avaliação das condições do processo, os ensaios também indicaram alguns inibidores, tais como, a acidificação do $\mathrm{pH}$, bem como elevados níveis de substrato. Cabe ressaltar que, no segundo planejamento as células foram inoculadas no meio reduzido sem qualquer etapa de aclimatação, alcançando $9,45 \mathrm{~g} / \mathrm{L}$ de acido $\mathrm{D}(-)$ lático através de processo descontinuo, durante 24 horas à temperatura de $37^{\circ} \mathrm{C}$.
\end{abstract}

\section{INTRODUÇÃO}

O ácido lático (ácido 2-hidroxipropiônico) é um ácido orgânico carboxílico de grande importância com aplicações nas indústrias alimentícia, farmacêutica, cosmética, têxtil e química, descoberto em 1780 pelo químico Carl Wilhelm Scheele (Abdel et al., 2011). Atualmente, devido às suas características de biodegradação, a sua utilização como intermediário na produção de plásticos biodegradáveis poly lactic acid PLA é uma das aplicações que apresentam maior interesse industrial (Nampoothiri et al., 2010), com a demanda estimada entre 130000-150000 toneladas por ano (Li et al.,2010; Sauer et al.., 2007). 
O ácido lático ocorre em duas formas isoméricas, ácido L (+) lático e ácido D (-) lático e pode ser obtido por síntese química, tendo como produto uma mistura racêmica; como também pode ser obtido pela ação fermentativa de bactérias, fungos e leveduras, onde, dependendo do microrganismo e das condições de operação será gerado um produto opticamente puro L(+) ou D(-) acido lático (Narayan et al., 2004; Li et al., 2010). Os processos fermentativos representam 90\% da produção mundial, sendo mais vantajosos, em sua maioria, através da fermentação descontínua (Hofvendahl \& Hahn, 2000), devido à possibilidade de utilizar substratos de baixo custo, além da redução da temperatura do processo (Gao et al., 2011). Ressalta-se, porém, que a síntese microbiana de ácido L (+) lático tem sido extensivamente pesquisada e reportada, inclusive a partir de substratos alternativos, enquanto a produção do ácido D (-) lático e suas aplicações tem sido pouco explorada (Nakano et al., 2012).

As bactérias láticas do gênero Lactobacillus são muito exigentes quanto às condições de crescimento, tendo necessidade de fontes de nitrogênio, vitaminas e sais minerais, devido à sua habilidade biossintética limitada (Wee et al., 2006). O metabolismo das bactérias láticas pode apresentar duas rotas principais, a homofermentativa, onde o consumo das hexoses ocorre através da via Embden-Meyerhof, a qual converte 1 mol de hexoses em 2 moles de ácido lático e 2 moles de ATP; e a heterofermentativa, onde o consumo das hexoses e pentoses ocorre pelas vias fosfogluconato/ fosfocetolase com a formação de quantidades equimolares de ácido lático, etanol e/ou acido acético, gás carbônico e ATP (Li et al., 2010; Hofvendahl e Hahn, 2000).

Neste contexto, no que tange à redução de custos para o processo de produção de acido $\mathrm{D}(-)$ lático, torna-se evidente a importância de se estabelecer um meio de cultivo reduzido, o qual, junto com a determinação das melhores condições operacionais, permita ter um processo mais eficiente, visando à possibilidade do uso de os materiais lignocelulósicos como matéria prima.

\section{MATERIAIS E METODOS}

Microrganismo: a linhagem Lactobacillus coryniformis sp. torquens utilizada neste trabalho foi obtida do banco de amostras ATCC 25600. O inóculo foi ativado em meio MRS comercial (manga-Rogosa-Sharpe) na concentração inicial de $10 \%(\mathrm{v} / \mathrm{v})$, a $37^{\circ} \mathrm{C}$ sob agitação de $120 \mathrm{rpm}$, em condições anaeróbias - mediante injeção de $\mathrm{CO}_{2}$ e $\mathrm{N}_{2-}$ por 12 horas. Para a conservação, as células foram mantidas em placas de petri (adicionadas de meio líquido MRS-Agar), em ultra-freezer a $-80^{\circ} \mathrm{C}$ (adicionadas de meio líquido MRS/ glicerol $50 \%$ ) e através de repiques periódicos em meio liquido.

Meios de cultivo e fermentação: O meio MRS empregado para o crescimento constitui-se dos seguintes componentes (g/L): peptona, 10; extrato de carne, 10; extrato de levedura, 5; glicose 20; tween-80, 1; citrato de amônia , 2; acetato de sódio, 5; sulfato de magnésio, 0,1; sulfato de manganês, 0.05 e fostato dipotasico, 2. Posteriormente, foram realizadas modificações na composição do meio para as avaliações experimentais.

Planejamentos experimentais: a ferramenta Desing- Expert 9.0.2 foi empregada para estabelecer os planejamentos e desenvolver a análise estatística. A metodologia Plackett- 
Burman foi utilizada para o screening e seleção dos principais componentes do meio MRS, através de variações de tais concentrações. No seguinte, buscando a avaliação das condições de crescimento, fermentação e possíveis inibições do processo, foi desenvolvido um planejamento fatorial completo $\mathbf{2}^{\mathbf{3}}$, onde os parâmetros analisados foram a agitação (rpm), o inoculo \% (v/v) e o conteúdo inicial de glicose (g/L). Esse planejamento foi desenvolvido a partir dos componentes resultantes do Plackett-Burman, sendo modificado o conteúdo de glicose inicial em três diferentes concentrações, conforme será mostrado na seção de Resultados \& Discussão. Os ensaios foram conduzidos por processo descontínuo, em frascos agitados com volume de trabalho de $50 \mathrm{~mL}$, sem controle de $\mathrm{pH}$, durante 24 horas à temperatura de $37^{\circ} \mathrm{C}$ em condições anaeróbias.

Determinações analíticas: as concentrações de substrato e produtos foram quantificadas pelo método analítico de cromatografia líquida de alta eficiência (CLAE) utilizando o sistema cromatográfico (WATERS). A identificação do isômero optico $\mathrm{D}(-)$ lático foi feita por cromatografia quiral, através do detector ultra-violeta (UV/VIS) - 254nm e fase móvel $\mathrm{CuSO}_{4} 0,001 \mathrm{~mol} / \mathrm{L}$. A produção de biomassa foi determinada pela técnica do peso seco correlacionada com a medida da absorbância (densidade óptica) em espectrofotômetro UV1800 Shimadzu a $600 \mathrm{~nm}$.

\section{RESULTADOS}

As etapas de crescimento e propagação foram desenvolvidas em meio de crescimento comercial MRS (concentração inicial de glicose $20 \mathrm{~g} / \mathrm{L}$ ), o qual é rico em componentes nutricionais. Contudo, uma vez que esse caldo apresenta um elevado valor comercial, tornando o seu uso em escala industrial inviável, o presente estudo buscou pela redução de tais componentes, bem como pela otimização do meio de cultivo e fermentação. Inicialmente, o microrganismo apresentou uma fase de adaptação de três horas, seguida da propagação, alcançando a densidade celular de 4,42 g/L e 5,11 g/L, assim como 17,29 g/L e 16, $35 \mathrm{~g} / \mathrm{L}$ de acido lático, respectivamente. $\mathrm{O}$ perfil de produção do microrganismo L. coryniformis torquens corresponde com o associado ao crescimento celular, sendo o acido $\mathrm{D}(-)$ lático o principal produto, identificado mediante cromatografia quiral como se presenta na figura 1.

a. Cromatograma padrão dos isômeros do acido lático (coluna quiral)

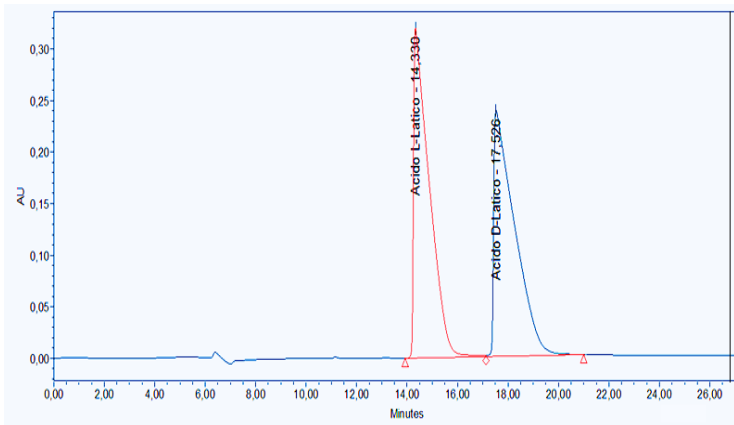

b. Acido D(-) lático produzido por Lactobacillus coryniformis sp. torquens (identificação pela cromatografia quiral)

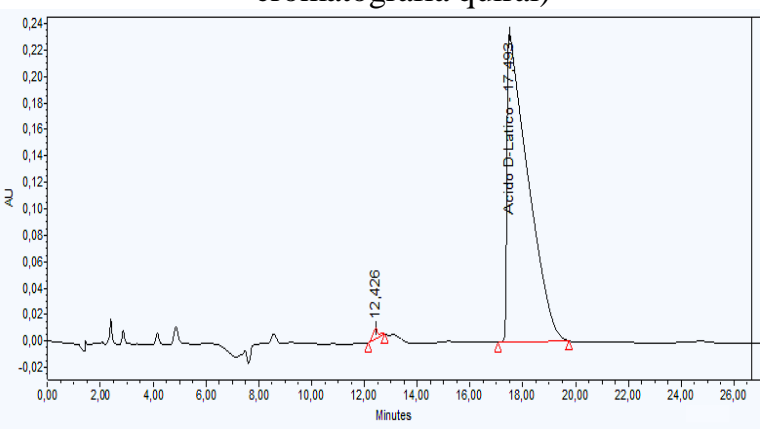

Figura 1 - Identificação do isômero D(-) lático por cromatografia quiral 


\subsection{Efeitos dos componentes do meio na produção do acido lático}

A tabela 1 apresenta os resultados de crescimento celular de acordo com o planejamento desenvolvido para avalição do efeito dos 10 componentes do meio sintético, através de um nível de confiança de $95 \%$. O extrato de carne, a glicose, o acetato de sódio e o sulfato de magnésio foram considerados os mais significativos de acordo com os resultados estatísticos apresentados na tabela 2, que mostra o efeito e a porcentagem de contribuição de cada componente.

Tabela 1- Planejamento Plackett-Burman para avaliação dos componentes do meio

\begin{tabular}{ccccccccccccc}
\hline Experimento & F1 & F2 & F3 & F4 & F5 & F6 & F7 & F8 & F9 & F10 & D1 & $\begin{array}{c}\text { Densidade } \\
\text { celular (g/L) }\end{array}$ \\
\hline 1 & 1 & -1 & -1 & -1 & 1 & -1 & 1 & 1 & -1 & 1 & 1 & 1,75 \\
2 & -1 & 1 & 1 & -1 & 1 & 1 & 1 & -1 & -1 & -1 & 1 & 2,30 \\
3 & -1 & -1 & -1 & 1 & -1 & 1 & 1 & -1 & 1 & 1 & 1 & 2,34 \\
4 & 1 & 1 & 1 & -1 & -1 & -1 & 1 & -1 & 1 & 1 & -1 & 2,43 \\
5 & -1 & -1 & -1 & -1 & -1 & -1 & -1 & -1 & -1 & -1 & -1 & 0,83 \\
6 & 0 & 0 & 0 & 0 & 0 & 0 & 0 & 0 & 0 & 0 & 0 & 2,61 \\
7 & 1 & -1 & 1 & 1 & -1 & 1 & 1 & 1 & -1 & -1 & -1 & 2,33 \\
8 & -1 & 1 & -1 & 1 & 1 & -1 & 1 & 1 & 1 & -1 & -1 & 3,56 \\
9 & 1 & 1 & -1 & 1 & 1 & 1 & -1 & -1 & -1 & 1 & -1 & 1,95 \\
10 & 0 & 0 & 0 & 0 & 0 & 0 & 0 & 0 & 0 & 0 & 0 & 2,32 \\
11 & 1 & 1 & -1 & -1 & -1 & 1 & -1 & 1 & 1 & -1 & 1 & 1,21 \\
12 & -1 & 1 & 1 & 1 & -1 & -1 & -1 & 1 & -1 & 1 & 1 & 2,73 \\
13 & 0 & 0 & 0 & 0 & 0 & 0 & 0 & 0 & 0 & 0 & 0 & 2,01 \\
14 & 1 & -1 & 1 & 1 & 1 & -1 & -1 & -1 & 1 & -1 & 1 & 1,23 \\
15 & -1 & -1 & 1 & -1 & 1 & 1 & -1 & 1 & 1 & 1 & -1 & 0,92 \\
\hline
\end{tabular}

Nota: os valores apresentados correspondem ao tempo $24 \mathrm{hr}$ para todos os experimentos

Tabela 2- Resultados estatísticos para metodologia Plackett Burman

\begin{tabular}{lccc|ccc}
\hline & \multicolumn{3}{c|}{ Níveis reais } & \multicolumn{3}{c}{ Resultados Estatísticos } \\
\cline { 2 - 7 } Fatores avaliados (g/L) & -1 & 0 & 1 & $\begin{array}{c}\text { Efeito } \\
\text { Stdized }\end{array}$ & $\begin{array}{c}\text { Suma de } \\
\text { quadrados }\end{array}$ & $\begin{array}{c}\text { \% de } \\
\text { contribuição }\end{array}$ \\
\hline F1 Peptona & 1,000 & 5,500 & 10,000 & $-0,30$ & 0,26 & 3,41 \\
F2 Extrato de carne & 1,000 & 5,500 & 10,000 & 0,80 & 1,90 & 24,60 \\
F3 Extrato de levedura & 0,500 & 2,750 & 5,000 & 0,050 & $7,500 \mathrm{E}-0003$ & 0,097 \\
F4 Glicose & 10,000 & 25,000 & 40,000 & 0,78 & 1,84 & 23,78 \\
F5 Polisorbato & 0,100 & 0,550 & 1,000 & $-0,027$ & $2,133 \mathrm{E}-003$ & 0,028 \\
F6 Citrato de amônia & 0,200 & 1,100 & 2,000 & $-0,25$ & 0,18 & 2,36 \\
F7 Acetato de sódio & 0,500 & 2,750 & 5,000 & 0,97 & 2,84 & 36,72 \\
F8 Sulfato de magnésio & 0,010 & 0,055 & 0,010 & 0,24 & 0,17 & 2,17 \\
F9 Sulfato de manganês & 0,025 & 0,038 & 0,050 & $-0,033$ & $3,333 \mathrm{E}-003$ & 0,043 \\
F10 Fosfato dipotássico & 0,200 & 1,100 & 2,000 & 0,11 & 0,036 & 0,47 \\
\hline
\end{tabular}

O extrato de carne, um dos fatores que apresentou significância estatística, é uma fonte de nitrogênio complexa com custo econômico considerável, mas contribui na redução do tempo de produção (Chauhan et al., 2007), favorecendo a produtividade do processo, além de conter vitaminas B que suprem os requerimentos nutricionais. Uma vez que as baterias do 
gênero Lactobacilluss têm necessidades nutricionais complexas por sua habilidade biossintética limitada (Wee et al., 2006). Uma vez que as baterias do gênero Lactobacilluss têm necessidades nutricionais complexas por sua habilidade biossintética limitada (Wee et al., 2006). O extrato de levedura foi incluso na seleção de componentes por ser fonte de vitaminas, aminoácidos e fonte de nitrogênio adicional ao extrato de carne, mesmo não tendo sido indicado pelo planejamento. Neste trabalho, a peptona não se mostrou significativa para a produção de acido lático utilizando o microrganismo em estudo, diferente do que foi reportado por Chauhan et al. (2007) para as linhagens Lactobacillus plantarum NCIM 2084 e Lactobacillus sp. KCP01, o que poderia favorecer economicamente o processo de produção de acido lático.

A falta de controle do $\mathrm{pH}$ reduz a produção do acido lático por Lactobacillus coryniformis torquens, portanto, é necessária a manutenção do mesmo em torno de 5,0-7,0 (Hofvendahl e Hahn, 2000). Desta forma, como os ensaios foram desenvolvidos sem o controle deste fator, o processo foi iniciado com o $\mathrm{pH}$ neutro e finalizado em torno de 3 , valor fortemente ácido e inibindo o metabolismo celular (Hofvendahl e Hahn, 2000 e Abdel et al., 2011). Ademais, os valores de crescimento celular foram reduzidos em comparação ao meio comercial, o que aponta para sensibilidade do microrganismo à variação das concentrações dos nutrientes; sendo necessárias posteriores etapas de adaptação ao meio reduzido com o fim de aumentar o crescimento celular e, conseguintemente, a produção do acido $\mathrm{D}(-)$ lático.

\subsection{Condições de crescimento e fermentação}

Os resultados do planejamento fatorial para avaliação das condições de crescimento, fermentação e possível inibição pelo substrato se apresentam na tabela 3 . O melhor resultado corresponde ao experimento 5 (glicose inicial de $20 \mathrm{~g} / \mathrm{L}$, sem agitação e inoculo de $10 \% \mathrm{v} / \mathrm{v}$ ), alcançando a densidade celular de 2,13 (g/L) e produção de acido $\mathrm{D}(-)$ lático de 9,45 (g/L). A menor produção ocorreu no experimento 4 (glicose inicial de $70 \mathrm{~g} / \mathrm{L}$, agitação de $200 \mathrm{rpm}$ e inoculo de $5 \% \mathrm{v} / \mathrm{v})$.

Tabela 3- Crescimento celular e produção de acido $\mathrm{D}(-)$ em processo descontinuo

\begin{tabular}{ccccccc}
\hline Experimento & $\begin{array}{c}\text { Glicose } \\
\text { inicial (g/L) }\end{array}$ & $\begin{array}{c}\text { Agitação } \\
\text { rpm }\end{array}$ & $\begin{array}{c}\text { Inoculo } \\
\text { \%(v/v) }\end{array}$ & $\begin{array}{c}\text { Densidade } \\
\text { celular (g/L) }\end{array}$ & $\begin{array}{c}\text { Acido } \\
\text { lático (g/L) }\end{array}$ & $\begin{array}{c}\text { Acido lático } \\
\text { predito (g/L) }\end{array}$ \\
\hline 1 & 20 & 0 & 5 & 1,97 & 9,10 & 8,96 \\
2 & 70 & 0 & 5 & 1,84 & 7,38 & 7,42 \\
3 & 20 & 200 & 5 & 2,12 & 6,98 & 7,20 \\
4 & 70 & 200 & 5 & 1,94 & 6,76 & 6,64 \\
5 & 20 & 0 & 10 & 2,13 & 9,45 & 9,59 \\
6 & 70 & 0 & 10 & 1,87 & 8,08 & 8,04 \\
7 & 20 & 200 & 10 & 1,93 & 8,04 & 7,82 \\
8 & 70 & 200 & 10 & 1,93 & 7,15 & 7,27 \\
9 & 45 & 100 & 7,5 & 2,03 & 7,88 & 7,71 \\
10 & 45 & 100 & 7,5 & 1,96 & 7,47 & 7,71 \\
11 & 45 & 100 & 7,5 & 1,91 & 7,77 & 7,71 \\
\hline
\end{tabular}

Nota: os valores apresentados correspondem ao tempo $24 \mathrm{hr}$ para todos os experimentos 
Tendo como resposta a produção do acido $\mathrm{D}(-)$ lático, a análise estatística mediante a ferramenta Desing- Expert 9.0.2, mostra que os três fatores avaliados -glicose inicial do processo, agitação e percentual de inoculo- têm influência significativa, assim como a interação glicose-inoculo, mostrando que os fatores não trabalham de forma totalmente independente (tabela 4).

Tabela 4- Resultados estatísticos para planejamento fatorial

\begin{tabular}{cccc}
\hline Fonte & Efeito Stdized & $\begin{array}{c}\text { Suma de } \\
\text { quadrados }\end{array}$ & $\begin{array}{c}\text { \% de } \\
\text { contribuição }\end{array}$ \\
\hline A- Glicose & -1.05 & 2.21 & 31.45 \\
B- Agitação & -1.27 & 3.23 & 46.01 \\
C-Inoculo & 0.63 & 0.78 & 11.14 \\
A-B & 0.50 & 0.49 & 6.99 \\
A-C & -0.080 & 0.013 & 0.18 \\
B-C & 0.10 & 0.020 & 0.29 \\
A-B-C & -0.26 & 0.13 & 1.85 \\
Curvatura & -0.17 & 0.056 & 0.80 \\
Lack of Fit & -1.05 & 0.000 & 0.000 \\
Erro puro & -1.27 & 0.090 & 1.28 \\
\hline
\end{tabular}

A análise de variância (ANOVA) tendo em conta os fatores A, B, C e a interação A-B (glicose, agitação, inoculo e glicose-agitação, respectivamente) foi desenvolvido para descrever a relação entre as variáveis e suas respostas na produção de acido lático, nas faixas avaliadas. Os resultados na tabela 5 mostram que o modelo, assim como os fatores, são significativos, pois apresentaram "Prob $>$ F" menor de 0,005 ; os pontos centrais estão inclusos no modelo, tendo o valor de Fisher para Lack of Fit de 1,22, sem significância em relação ao erro puro; a curvatura não apresentou significância, não sendo incluída no modelo.

Tabela 5. Resultados do ANOVA para produção de acido $\mathrm{D}(-)$ lático

\begin{tabular}{cccccc}
\hline Fonte & $\begin{array}{c}\text { Suma de } \\
\text { quadrados }\end{array}$ & df & $\begin{array}{c}\text { Quadrado } \\
\text { médio }\end{array}$ & Valor F & $\begin{array}{c}\text { Valor P } \\
\text { Prob > F }\end{array}$ \\
\hline Model & 6.70 & 4 & 1.68 & 32.50 & 0.0003 \\
A-Glicose & 2.21 & 1 & 2.21 & 42.77 & 0.0006 \\
B-Agitação & 3.23 & 1 & 3.23 & 62.57 & 0.0002 \\
C-Inoculo & 0.78 & 1 & 0.78 & 15.15 & 0.0081 \\
AB & 0.49 & 1 & 0.49 & 9.50 & 0.0216 \\
Residual & 0.31 & 6 & 0.052 & - & - \\
Lack of Fit & 0.22 & 4 & 0.055 & 1.22 & 0.4975 \\
Erro puro & 0.090 & 2 & 0.045 & - & - \\
Cor Total & 7.01 & 10 & - & - & - \\
\hline
\end{tabular}

O modelo de regressão gerado para produção de acido lático (equação 1) apresentou 0,9559 de $\mathrm{R}^{2}$; 0,9265de $\mathrm{R}^{2}$ ajustado; assim como $\mathrm{R}^{2-}$ Predito de 0,8255 , indicando bom comportamento para predição nas faixas avaliadas como se indica nos valores preditos apresentados na tabela 3 . 
Os resultados da tabela 3 mostram que, para a faixa avaliada de glicose inicial, o microrganismo Lactobacillus coryniformis sp. torquens apresentou uma queda na produção do acido $\mathrm{D}(-)$ lático, bem como da densidade celular para as concentrações mais elevadas de glicose, em $70 \mathrm{~g} / \mathrm{L}$. Quando comparadas à performance do microrganismo em menores valores desse açúcar, em $20 \mathrm{~g} / \mathrm{L}$, sob as mesmas condições de agitação e adição de inoculo, houve uma redução de $9.45 \mathrm{~g} / \mathrm{L}$ para $8.08 \mathrm{~g} / \mathrm{L}$ na produção do ácido lático, simultaneamente ao aumento da concentração de glicose do menor nível para o maior nível do planejamento. Este comportamento pode ser atribuído a uma possível inibição pelo substrato, conforme já foi relatado na literatura por Abdel et al., 2011.

Os motivo pelos quais houve uma redução na produção de acido $\mathrm{D}(-)$ lático podem estar relacionados à falta de controle de $\mathrm{pH}$, assim como à elevada necessidade nutricional requerida pelo microrganismo em questão, conforme descrito nos resultados do planejamento Plackett-Burman. Neste contexto, a acidificação do meio prejudicou a produção de biomassa devido à inibição pelos produtos formados, os quais afetam severamente o metabolismo celular. Adicionalmente, os ensaios foram realizados a partir de um meio de fermentação reduzido, cuja composição e concentração $(\mathrm{g} / \mathrm{L})$ dos nutrientes apresentam-se a seguir: extrato de carne, 10; extrato de levedura, 5; acetato de sódio, 5; sulfato de magnésio, 0,1; com concentração inicial de glicose na faixa avaliada entre 20 e 70, sem qualquer adaptação às novas concentrações nutricionais sendo afeitada a capacidade de crescimento e produção do microrganismo.

Futuramente, os componentes selecionados serão otimizados mediante planejamentos fatoriais fracionados ou rotacionais com pontos centrais, tendo assim um meio que atenda às necessidades nutricionais do microrganismo e permita a redução de custos na produção industrial. Junto com a redução e otimização dos componentes do meio, é necessária a utilização de substratos alternativos como fontes de carbono onde a produção de acido lático vai depender do tipo de açúcar, microrganismo e tipo de processo (Hofvendahl e Hahn, 2000), para o caso do Lactobacillus coryniformis sp. torquens, a produção do acido $\mathrm{D}(-)$ lático segue a rota homofermentativa sendo o açúcar fermentável, a glicose. Tendo esta referencia, os materiais lignocelulósicos como o bagaço de cana, cuja fração de celulose ocorre torno de $36 \%$, se apresentam como alternativa para produção de acido lático de segunda geração.

\section{CONCLUSÕES}

O controle do $\mathrm{pH}$ mostrou-se essencial para aumentar a produção do acido lático, pois a produção associada ao crescimento é fortemente inibida pela redução do mesmo, consequência da formação do produto, sendo necessária a adição de uma solução com o pH básico, no intuito de manter a viabilidade celular, elevando assim, a produtividade volumétrica do processo. 
A exigente necessidade nutricional do microrganismo em estudo se reflexa em baixas produções de ácido lático em meios reduzidos, sendo necessários novos planejamentos para aperfeiçoar as concentrações dos componentes do meio - extrato de carne, glicose, acetato de sódio, sulfato de magnésio e extrato de levedura- resultantes da metodologia PlackettBurman. Simultaneamente, são necessárias etapas de aclimatação no intuito de promover melhor adaptação da linhagem ao novo meio, promovendo maiores concentrações de biomassa e de produto.

O fato da bactéria Lactobacillus coryniformis sp. torquens ter apresentado crescimento significativo com a ausência de agitação orbital é uma vantagem para o processo de produção industrial, sendo possível a redução de custos na etapa de ativação e propagação; no entanto, a agitação moderada durante o processo fermentação é necessária para reduzir a formação de gradientes de concentração.

\section{REFERÊNCIAS}

ABDEL-RAHMAN, M; TASHIRO, Y; SONOMOTO, K. Lactic acid production from lignocellulose-derived sugars using lactic acid bacteria: Overview and limits. Journal of Biotechnology 156 (2011) 286-301. 2011

CHAUHAN, K; TRIVEDI, U; PATEL, K. Statistical screening of médium componentes by Plackett-Burman design for lactic acid production by Lactobacillus sp, KCP01 using date juice. Bioresource Technology 98 (2007) 98-103. 2007.

GAO, C.; MA, C.; XU, P. Biotechnological routes based on lactic acid production from biomass. Biotechnology Advances v. 29, p. 930-939, 2011.

HOFVENDAHL, K.; HAHN-HAGERDAL, B. Factors affecting the fermentative lactic acid production from renewable resources1. Enzyme and Microbial Technology, v.26, p. 87107, 2000.

LI, Y.; CUI, F. Microbial lactic acid production from renewable resources. Sustainable Biotechnology. doi: 10.1007/978-90-481-3295-9_11, 2010.

NAMPOOTHIRI, K; NAIR, N; PAPPY R. An overview of the recent developments in polylactide (PLA) research. Bioresource Technology 101 (2010) 8493-8501, 2010

SAUER, M; PORRO, D; MATTANOVICH, D; BRANDUARDI, P. Microbial production of organic acids: expanding the markets. Cell Press, Trends in Biotechnology Vol 26- No 2, p. 100-108, 2007 